\title{
Detection and Discrimination of Islanding and Faults in distribution system with Distributed Generation by using Wavelet based Alienation approach
}

\author{
K. Kamala Devi ${ }^{1}$, Abdul Gafoor Shaik ${ }^{2}$ \\ ${ }^{1}$ Department of Electrical and Electronics Engineering, Bapatla Engineering College, Bapatla-522101, India \\ ${ }^{2}$ Department of Electrical Engineering Indian Institute of Technology Jodhpur, Jodhpur-769008, India
}

\begin{tabular}{l}
\hline Article Info \\
\hline Article history: \\
Received January 05, 2019 \\
Revised May 01, 2019 \\
Accepted Sep 05, 2019 \\
\hline
\end{tabular}

\section{Keyword:}

Distributed generation

Islanding

Fault detection

Alienation coefficients

Distribution network

Approximation coefficients

\begin{abstract}
This paper presents a wavelet transform based alienation technique for the protection of a radial 5 bus distribution system integrated with four wind type doubly fed Induction generators (DFIG).This technique is used to detect islanding condition and faults, classification of faults and their discrimination. Islanding is simulated at point of common coupling (PCC) and faults are simulated at each DG bus of the network. Daubechies wavelet transform has been used to decompose the current signals to get approximate coefficients. The Alienation coefficients of these approximate decompositions are termed as islanding and fault indexes. These indexes have been compared with predetermined threshold to detect islanding and faults. The same threshold value is utilized to discriminate transients associated with islanding and fault. Alienation coefficients at each bus over a half cycle window clearly detect both islanding and fault. Testing of the proposed algorithm has been carried out for various angles of incidence. Hence, the proposed algorithm is more effective and successful for finding the islanding condition as well as faults in distribution system with distributed generation.
\end{abstract}

Copyright $(0) 2019$ Institute of Advanced Engineering and Science. All rights reserved.

\section{Corresponding Author:}

K. Kamala Devi,

Assistant Professor,

Department of Electrical and Electronics Engineering,

Bapatla Engineering College,

Bapatla-522101, India.

Email: kamaladevi.bec@gmail.com

\section{INTRODUCTION}

Demand for electrical power is tremendously growing globally. However, the generation of electrical power could not meet the growing demand. On the other hand, due to the power system deregulations, new opportunities have been opened to small power generating plants close to the customers. This system of generation is called dispersed generation or distributed generation. Usually, resources such as wind, Photo Voltaic (PV), combined heat and power (CHP) and diesel are used in distributed generation. The improvement of the voltage profile as well as power quality of the system is done by penetration of Multiple DGs in distribution system [1]. The penetration of DGs with the grid can lead to develop several technical issues. If the Grid is intentionally or accidently disconnected from the distribution system, but the local loads and system are continuously feed by the distributed generation, it is said to be islanding condition. It may pose a danger to the maintenance personnel, public safety, equipment and customers in the distribution system etc. Moreover, unsynchronized reclose of the grid to the distribution system may cause damage to the power electronic conditioning equipment of the DG system. It is necessary to detect this condition and take appropriate steps to avoid complex issues associated with islanding. The DG must be disconnected as per the IEEE929-1988 standard as soon islanding is detected $[2,3]$. A comprehensive review on different methods of Islanding detection for DG can be seen elsewhere $[4,5]$. 
An active islanding technique has been used by H. Karimi and A. Yazdani [6] for a distributed resource unit coupled with a utility grid by injection of negative sequence current with Voltage Source Converter (VSC) controller. S. R. Samantha Ray and Trupti Mayee Pujhari developed a wavelet based approach for detection of islanding by deriving the negative sequence of current and voltage [7]. Velasco et al used an active anti islanding technique by inculcating interference at inverter output and by measuring the voltage at the point of customary coupling and varies with impedance of PCC during islanding condition [8]. A new algorithm has been proposed by F. Hashemi, A. Kazemi, S. Soleymani on the basis of quantity of values of d-component and q-component [9]. Aziah Khamis et al proposed a method for distribution systems with distributed generator to detect islanding with the help of neural network and phase space technique [10]. Raza, Safdar et al gave a detailed review on application of pattern recognition techniques like ANN to detect islanding condition [11]. Walid G. Morsi et al introduced a wavelet packet transform based islanding detection technique by using an index called node rate of change of the output power of the DG [12]. H. K. Karegar proposed a passive islanding detection method by measuring and decomposing voltage signals with discrete wavelet transform of Daubiches wavelet [13, 14].

Stability of the system can be maintained with the quick and accurate detection of faults, and supply also can be restored quickly which results in economy improvement and in power quality. Protection scheme for detection, classification and location of faults based on Wavelet transform was proposed by S. Abdul Gafoor, et al [15]. A protection scheme based on d1 coefficients of Haar wavelet was also proposed in the literature [16]. Fault detection and fault distance calculation in distributed system lines based on components of frequency spectrum with fault generated travelling waves was presented by Javad Sadeh [17]. Yuan Liao proposed a method based on bus impedance matrix to identify fault locations [18]. A. M. EI-Zonkoly proposed a protection scheme by tracing wavelet coefficients based entropy of the measured bus connections [1]. S. S. Gururajapathy H. Mokhilis studied effectiveness of different fault detection methods like artificial intelligence, fuggy logic, genetic algorithm etc [19]. Detection and location of high impedance faults in distribution systems by making use of wavelet discrete wavelet transform associated with neural network was also presented [20]. Rathore and Gafoor proposed alienation coefficient method based on wavelet coefficient for the fault detection in a transmission line [21]. Masoud and Mahfouz constructed an algorithm based on alienation coefficients of current signals for the protection of transmission line [22]. Chatterjee et al proposed a technique for detection and classification of transients on wavelet-network based algorithm [23]. J. U. Bhaskar et al proposed a wavelet fuzzy based protection scheme for a three terminal transmission system by using current signals [24]. Micro grid connected power system protection scheme based on wavelet approach is discussed by S. Chandra shekar et al[25]. A review was given on authentication techniques in smart grid by Malik Qasaimeh [26]. A.M shiddiq yunus et al discussed effectiveness of DFIG to weakgrids over FCWECS [27]. A firefly algorithm for frequency stabilization in wind power system was proposed by Aryonugroho [28].

This paper presents to design and develop a technique to detect islanding condition in order to eliminate complex issues associated with islanding such as safety of end users and equipment and classify faults to provide the protection system which can operate the relays in quarter cycle to isolate the faulty feeder with minimum time even in the presence of wind power generation. The proposed work is based on the wavelet transform alienation coefficients for the detection of islanding condition, faults and their classification in the power system with the wind form based distributed generation. This technique narrates the signal in timefrequency domain, which will help in the extrication of vital information of the signal even under transient conditions. However, it is required to propose high speed protection scheme with less computational complex for detection and classification of faults in distribution systems. The proposed algorithm in this work can detect and classify the faults within a quarter cycles.

The structure of this paper is as following. Section 2 describes proposed methods used for the algorithm. In section 3 proposed algorithms is explained. Section 4 presents results and discussion including detection of islanding, variation of islanding index with different incidence angle, detection and classification of faults, variation of fault index with fault incidence angles. Conclusions are presented in section 5 .

\section{ALIENATIONS BASED ON WAVELET APPROXIMATION COEFFICIENTS}

\subsection{Wavelet transform}

Analyzing the signal in frequency band and non-uniform division of frequency domain can be done by Wavelet Transform as it utilizes the short window at high frequencies and low window at low frequencies. Wavelet Transform is defined as a series of a function $\{\mathrm{h}(\mathrm{n})\}$ (low pass filter) and $\{\mathrm{g}(\mathrm{n})\}$ (high pass filter). The scaling and wavelet functions are explained by the equations given below.

$$
\begin{aligned}
& \emptyset(t)=\sqrt{2} \sum h(n) \varphi(2 t-n) \\
& \Psi(t)=\sqrt{2} \sum g(n) \psi(2 t-n)
\end{aligned}
$$

Where, $\mathrm{g}(\mathrm{n})=(-1)^{\mathrm{n}} \mathrm{h}(1-\mathrm{n})$ 


\subsection{Alienation coefficients}

In the proposed algorithm, current signals are sampled over a length of half cycle. Wavelet transform are applied to these samples and analysed to get required approximation coefficients. The alienation coefficient on the basis of approximation sampling (Coefficients) is calculated by:

$$
A_{A}=1-r_{a}^{2}
$$

Where, $r_{\mathrm{a}}$ is the correlation coefficient measured based on approximation coefficients which can be calculated as given below.

$$
r_{a}=\frac{N_{S}\left(\sum x_{a} y_{a}\right)-\left(\sum x_{a} \sum y_{a}\right)}{\sqrt{\left[N_{s} \sum x_{a}^{2}-\left(\sum x_{a}\right)^{2}\right]\left[N_{s} \sum y_{a}^{2}-\left(\sum y_{a}\right)^{2}\right.}}
$$

Where, $N_{s}$ is the number of samples per half cycle, $x_{a}$ is the absolute value of samples at $\mathrm{t}_{0}, \mathrm{y}_{\mathrm{a}}$ is the absolute value of samples considering previous moving window of half cycle. The variance between two signals is defined as the alienation coefficient. Its value lies between 0 and 1 .

\subsection{Weighted alienation coefficients}

It is needed to apply the concept of weighted alienation coefficients to detect the transients of faults at PCC when faults occurred at DGs. Simple arithmetic gives equal importance to all values in a series. In some cases, all the values in a series do not give same weightage. In such cases weighted average is more suitable for calculations. The concept of average of weighted Alienation coefficients is as follows. It is used to increase the relative importance of any quantity (of our interest) with respect to other quantities. For which each value is multiplied by a weight according to its importance. The weighted average for any input $\mathrm{x}$ can be computed by using the following equation (5) and procedure.

$$
\bar{x}=\operatorname{avg} \sum_{i=1}^{i=5} W i X i
$$

- $\quad \mathrm{i}=$ Total number of inputs.

- $\quad \mathrm{Xi}_{\mathrm{i}}$ is alienation coefficient at each bus of four DGs and PCC where, $\mathrm{i}=1,2,3,4,5$.

- $\operatorname{Get} \operatorname{Max}\left(\mathrm{x}_{1}, \mathrm{x}_{2}, \mathrm{x}_{3}, \mathrm{x}_{4}, \mathrm{x}_{5}\right)=\mathrm{n}$.

- Divide each alienation value of DGs and PCC by $n$ to get weights. The weights will be $\mathrm{x}_{\mathrm{i}} / \mathrm{n}=\mathrm{w}_{\mathrm{i}}$ where $\mathrm{i}=1$ to 5 .

- Multiply every alienation coefficient of four DGs and PCC with their respective weights (Wi).

- Then get average of these values for all the three phases.

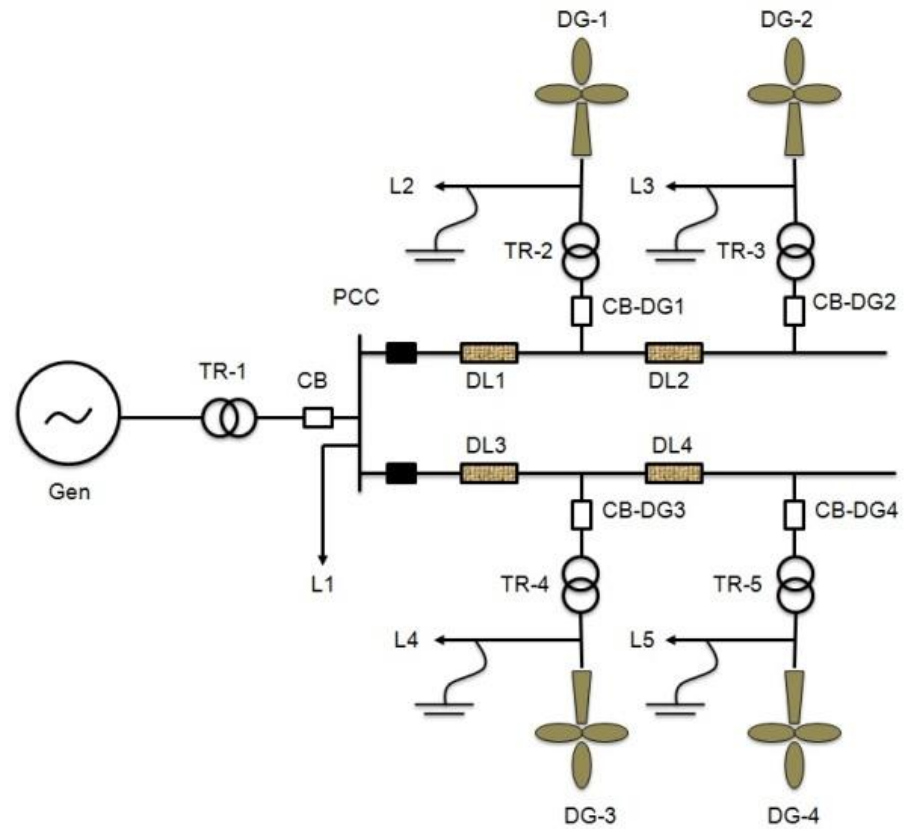

Figure 1. Single line diagram of the system 
Table 1. Parameters adopted from [7] in the present work.

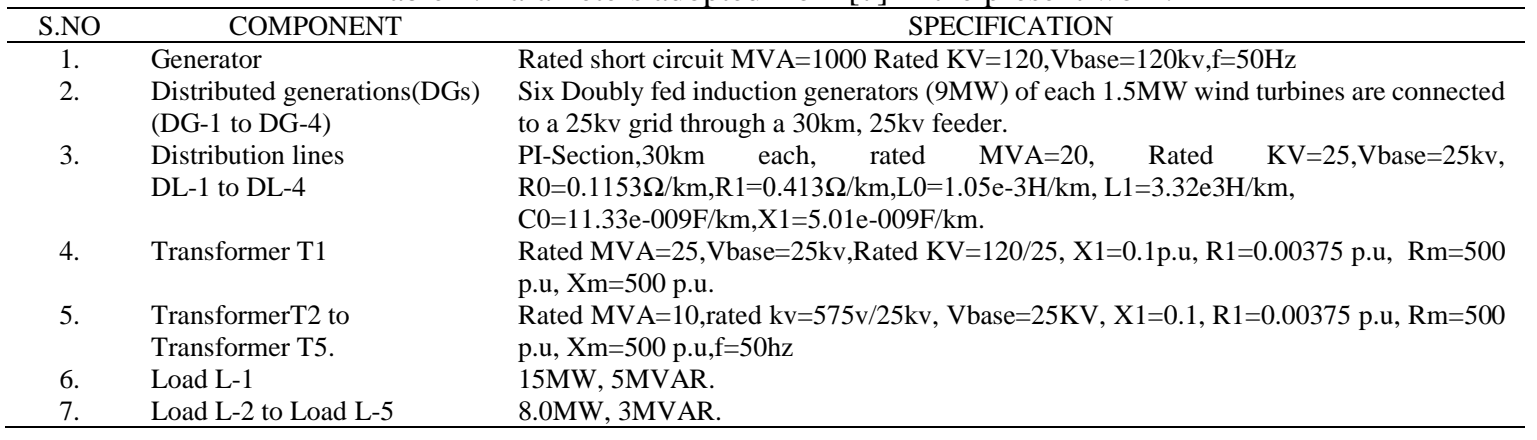

\section{PROPOSED ALGORITHM}

The system shown in Figure 1 has been studied with a base power 10 MVA contains radial distributed system of 4 DG units (wind forms) which are connected to a main supply through a Point of Common Coupling (PCC) with an operating frequency of $50 \mathrm{~Hz}$. DG units 1 and 3 are placed at a distance of $30 \mathrm{~km}$ and 2 and 4 are placed at a distance of $60 \mathrm{~km}$ from the PCC of distribution lines of pi-sections respectively. The generator data, DGs, transformers as well as distribution of lines and loads are taken in to account from Ref. [6] and also mentioned in appendix. Figure 2 shows the flow chart of the proposed algorithm. The system has been simulated using MATLAB/SIMULINK as per Figure1. The sampling frequency of $6400 \mathrm{~Hz}$ is considered with 128 samples per cycle. The simulation was carried out for 25 cycles and run for $0.5 \mathrm{sec}(25$ cycles) and fault and islanding are simulated after 20 cycles (at $0.4 \mathrm{sec}$ ). Islanding is simulated by opening the PCC circuit breaker at the same time of fault initiation.

Initially Current signals obtained at each bus were decomposed by using Daubechies Wavelet for third level decomposition with a sampling frequency of $6400 \mathrm{~Hz}$. The approximation coefficients are obtained. The absolute values of approximation coefficients over a current window of a half cycle length are compared with those of previous window are utilized to compute alienation coefficients. Here, Alienation coefficients are treated as islanding index in case of islanding detection and as fault index in case of fault detection. The value of Alienation coefficients $\left(A_{a}\right)$ continues to be zero under normal conditions because the successive windows contain similar set of approximation coefficients and hence $\mathrm{A}_{\mathrm{a}}$ remains zero. Whereas, in the case of islanding and fault condition the approximate coefficient of current window should vary from those of preceding window of similar polarity. There would be a definite increase in the value of alienation coefficient from zero which indicates islanding or fault. At PCC, the fault indices of three phase currents have been obtained by averaging of weighted alienation coefficients of DGs and PCC. By comparing islanding index with threshold value and it is found that islanding index is less than threshold value to detect islanding condition. By comparing the fault index with a threshold value, the faulty phase can be detected. Therefore, faulty phase holds a fault index greater than the threshold value and the healthy phase holds a fault index less than a threshold value.

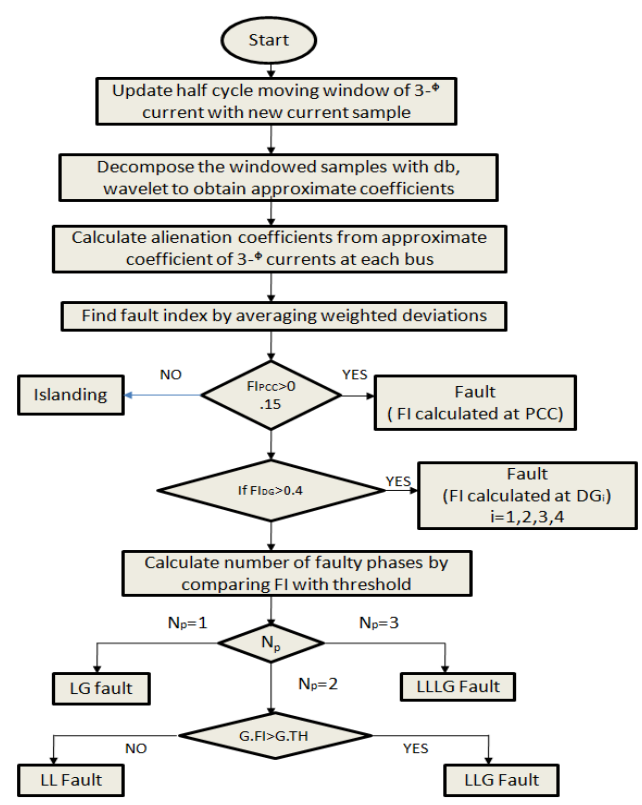

Figure 2. Flow chart of proposed algorithm 


\section{RESULTS AND DISCUSSION}

\subsection{Detection of islanding}

Figure 3 illustrates the detection of islanding at various DGs by opening circuit breaker at $0.4 \mathrm{sec}$ at PCC. From the detailed study and observations of the results, 0.4 is set as a threshold to detect the faults at DGs and 0.15 is set as a threshold to detect islanding and faults at PCC. Fig.3 (a), 3(b), 3(c), 3(d) illustrate variation of islanding index below the threshold which indicates islanding condition of all DGs for current signal.

(a)

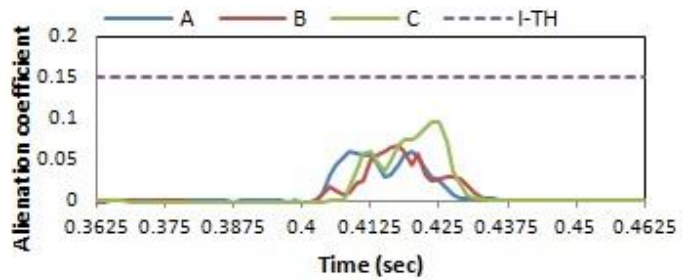

(c)

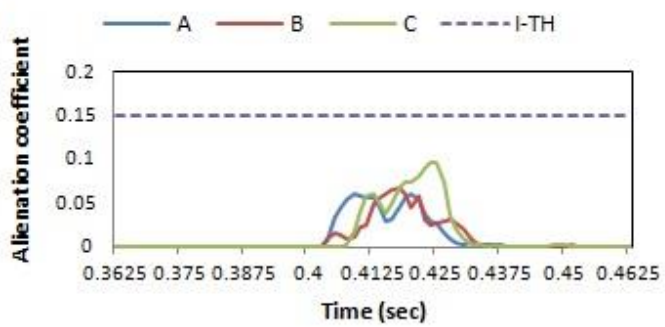

(b)

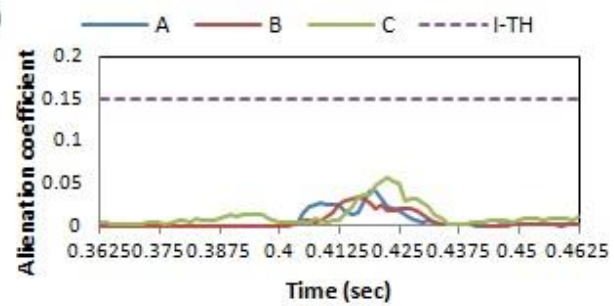

(d)

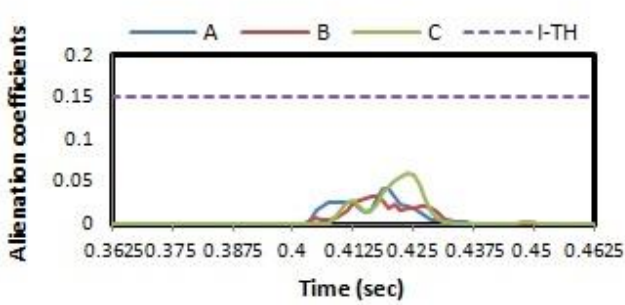

Figure 3. Variation of islanding indexes with time at a) DG-1 located at 30km from PCC, b) DG-2 located at $60 \mathrm{~km}$ from PCC, c) DG-3 located at 30km from PCC and d) DG-4 located at 60km from PCC.

(a)

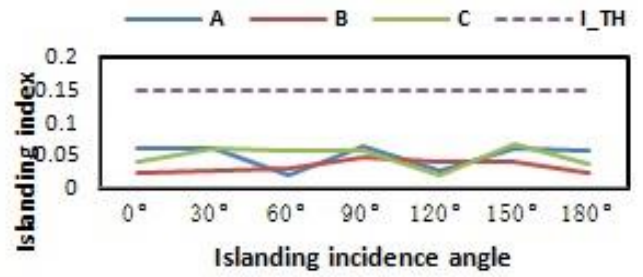

(c)

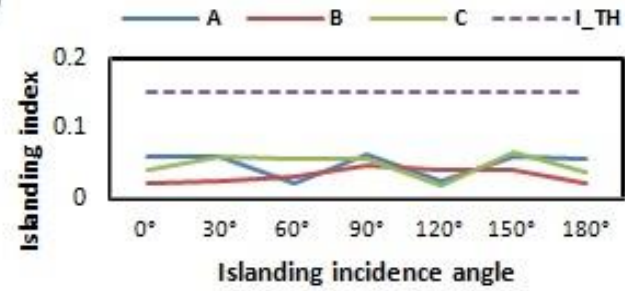

(b)

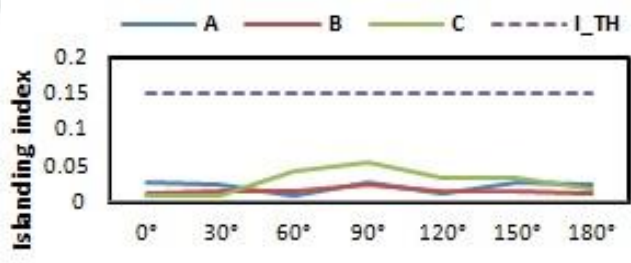

(d)

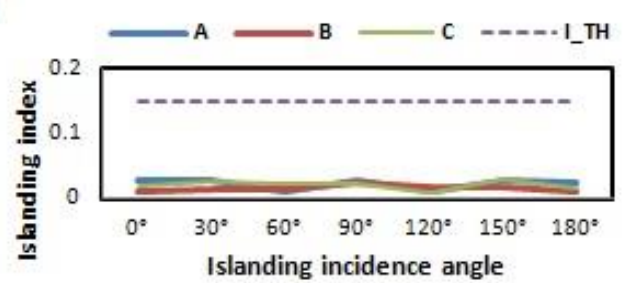

Figure 4. Variation of islanding indexes with islanding incidence angles at DG-1, b) DG-2, c) DG-3 and d) DG-4

\subsection{Variation of Islanding Index with incidence angles}

To test the present algorithm at definite intervals of $30^{\circ}$, islanding has been applied. The contrast of islanding indexes of the three phases with the angle of islanding incidence has been illustrated in Fig. 4. It is apparent from Fig. 4(a), 4(b), 4(c) and 4(d) that the islanding index is always lower than the threshold value of all DGs for various incidence angles which shows islanding condition. 


\subsection{Detection and classification of faults}

(a)

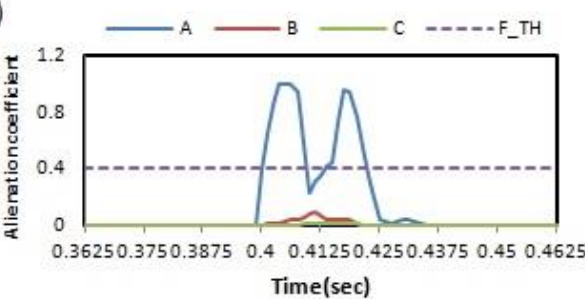

(c)

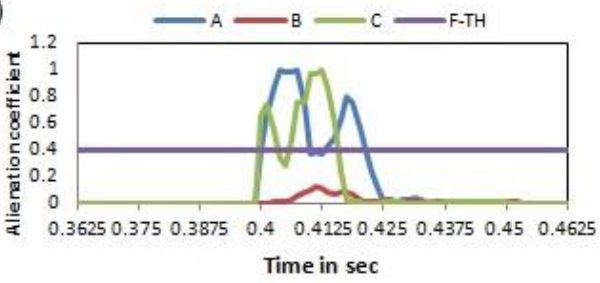

(b)

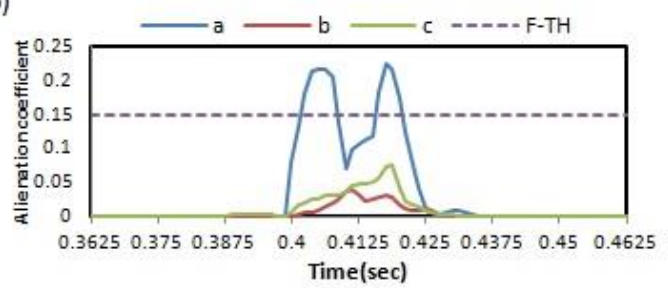

(d)

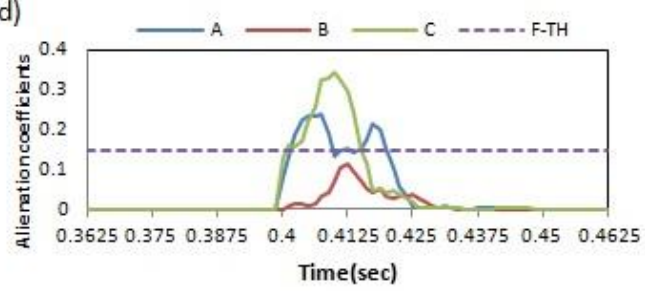

Figure 5. AG fault at a) DG-1, b) at PCC, c) CA fault at DG-1 and d) at PCC.

Simulation of faults has been done after 20-cycles for obtaining post fault transients for 5-cycles. The performance of proposed algorithm at various DGs and PCC for different faults at a distance of $30 \mathrm{~km}$ from PCC and DGs from each other is demonstrated in Figure 5 to Figure 9.

Figure 5 shows variation of fault indexes of three phase currents with time at DG1 and PCC. It has been observed from Fig. 5 (a) and Fig 5 (b) that the fault index of phase A is greater than the threshold and for those of phase $\mathrm{B}$ and phase $\mathrm{C}$ are lower than the threshold (F-TH). Thus the proposed scheme is identified and classified as single line to ground fault (AG) at DG-1 and PCC. It has been illustrated from Fig. 5 (c) and Fig 5 (d) that the fault index of phase $A$ and phase $\mathrm{C}$ are above the threshold and that of phase $\mathrm{B}$ is found to be below the threshold. Thus this fault is identified and classified as AC fault at DG-1 and its respective PCC.

(a)

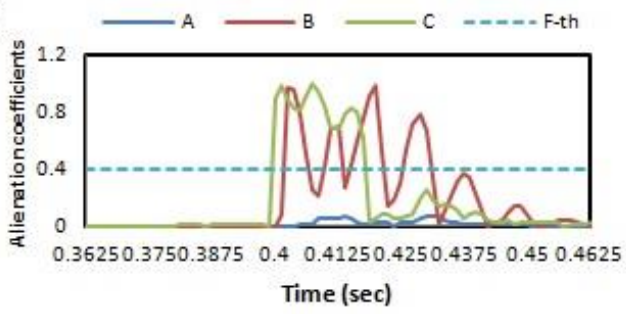

(c)

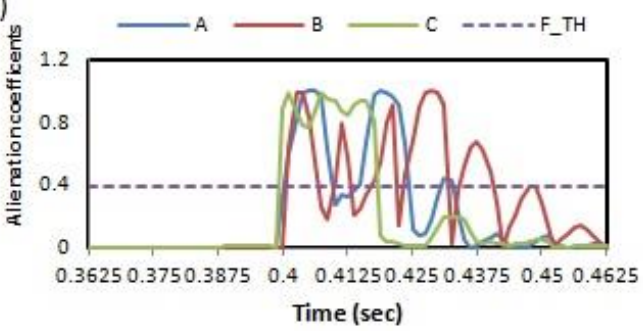

(b)

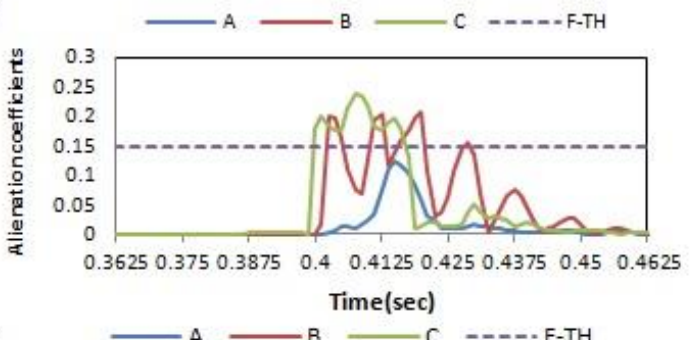

(d)

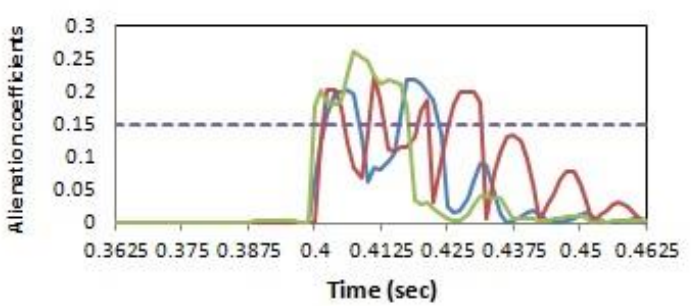

Figure 6. a) BCG fault at DG-2, b) at PCC, c) ABCG fault at DG-2 and d) at PCC

Figure 6 shows variation of fault index with time at DG2 and PCC. It is observed that from Fig.6(a) and Fig.6(b) the fault index of phase $\mathrm{B}$ and phase $\mathrm{C}$ are above the threshold value and fault index of phase $\mathrm{A}$ is below the threshold value which is evident that fault is double line to ground (BCG) fault. Similarly from Fig6(c) and 6(d) it is evident (ABCG) fault at DG2 and PCC.

Similarly Figure 7(a), 7(b) illustrated BG fault and figure.7(c),7(d) illustrated AB fault at DG3 and PCC. Fig 8(a), and Fig 8(b) illustrated (BC) fault where as Fig8(c) and Fig 8(d) illustrated line to ground fault (CG) at DG4 and PCC. Figure 9 depicts fault index vs time at PCC. From Fig 9(a) it was illustrated that the fault index of phase $\mathrm{A}$ and phase $\mathrm{C}$ are greater than the threshold and phase $\mathrm{B}$ is lower than the threshold value which was identified as line to line fault at PCC. Fig 9(b) illustrated that (ABG) fault at PCC. 
(a)

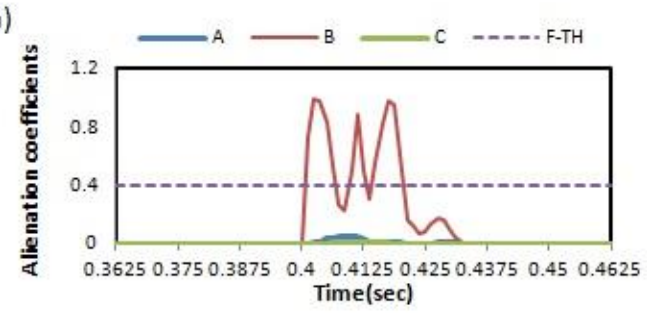

(c)

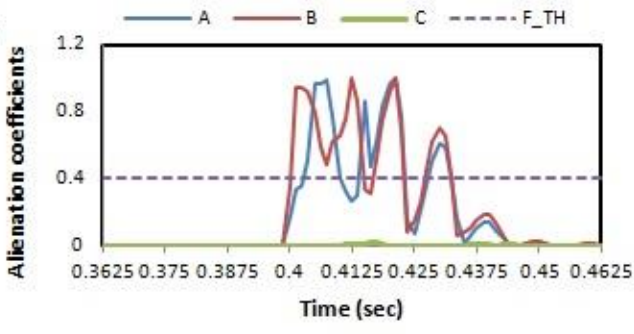

(b)

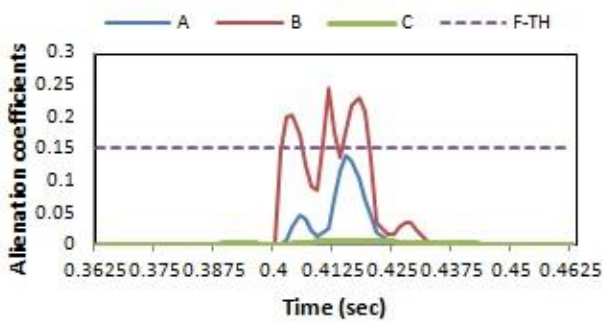

(d)

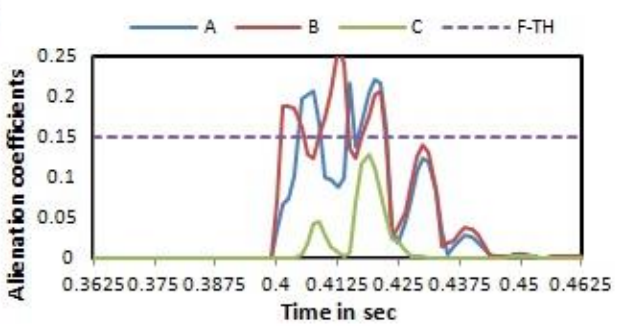

Figure 7. a) BG fault at DG-3, b) at PCC, c) ABG fault at DG-3 and d) at PCC

(a)

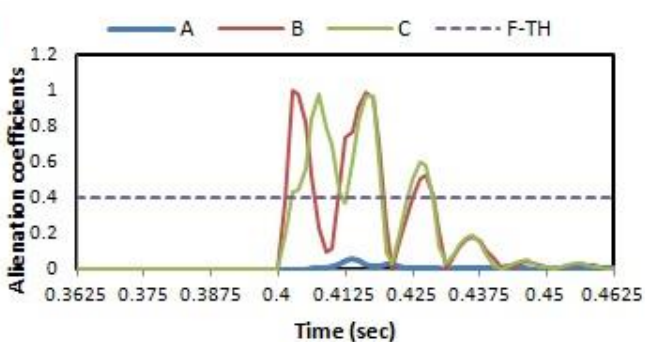

(c)

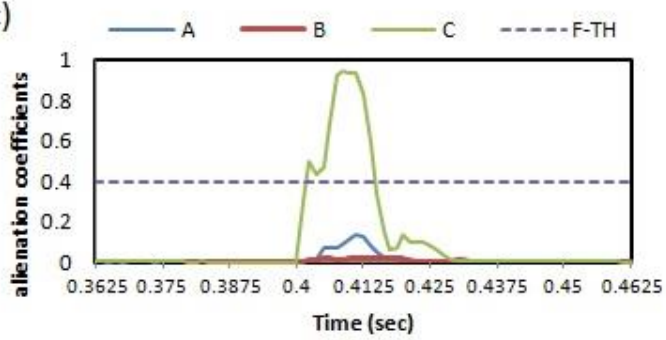

(b)

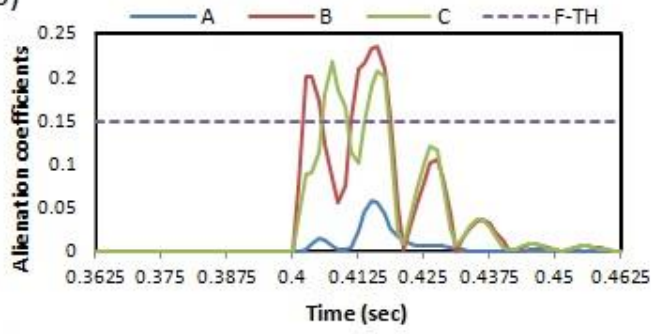

(d)

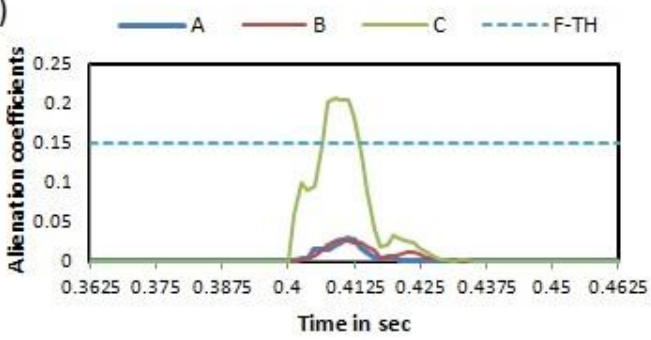

Figure 8.a) BC fault at DG-4, b) at PCC, c) CG fault at DG-4 and d) at PCC

(a)

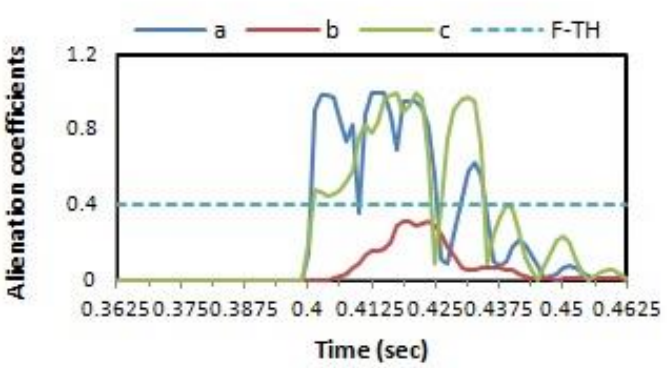

(b)

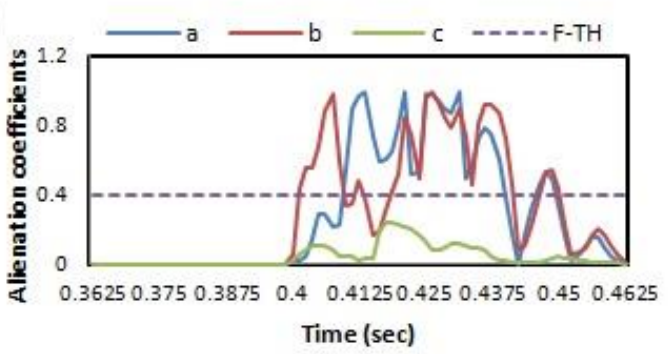

Figure 9.a) AC fault at PCC, b) AB fault at PCC

From the graphs it is observed that the healthy phase never cross the threshold value and faulty phase crosses the threshold value. Once fault index of any phase is greater than the threshold value, it is considered as faulty phase even though the fault index is lower than the threshold for a moment after detection of fault. Fault was detected within 16 samples at every DG and PCC. 


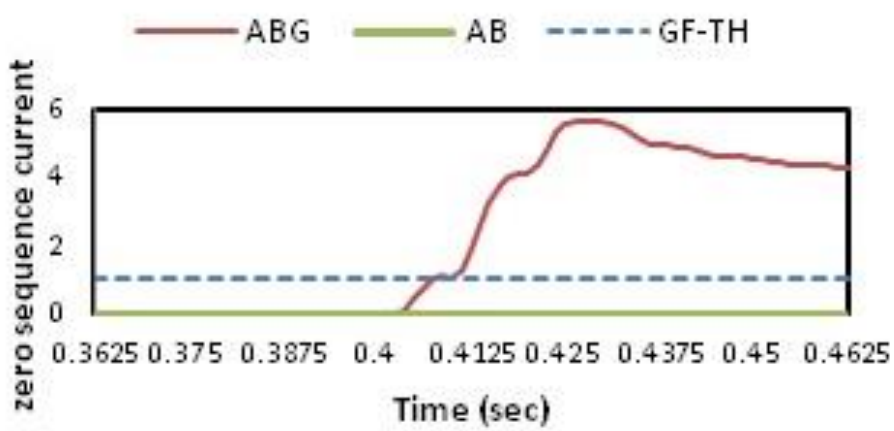

Figure 10. Discrimination between $\mathrm{AB}$ and $\mathrm{ABG}$ fault

(a)

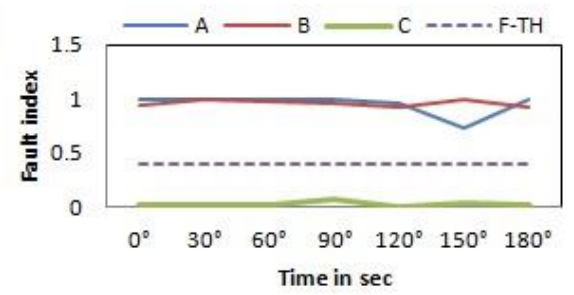

(c)

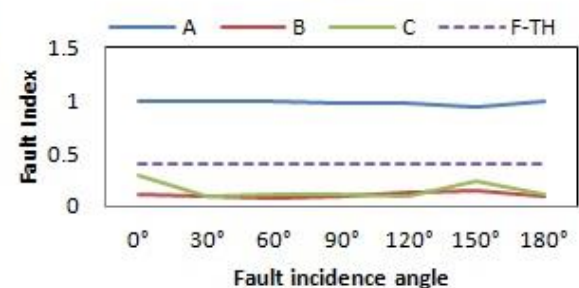

(e)

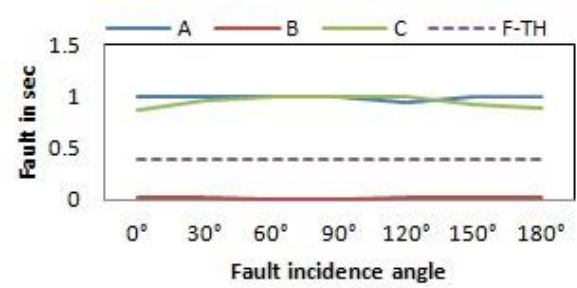

(g)

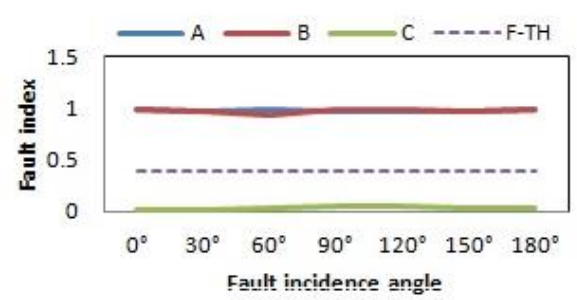

(i)

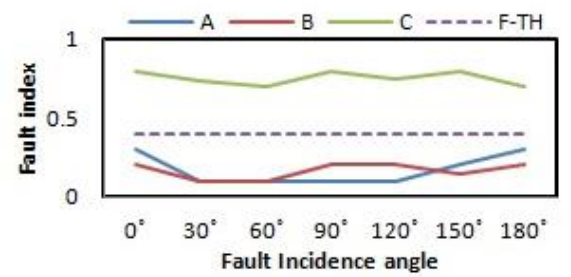

(b)

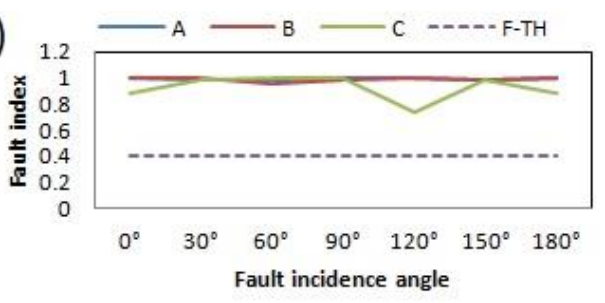

(d)

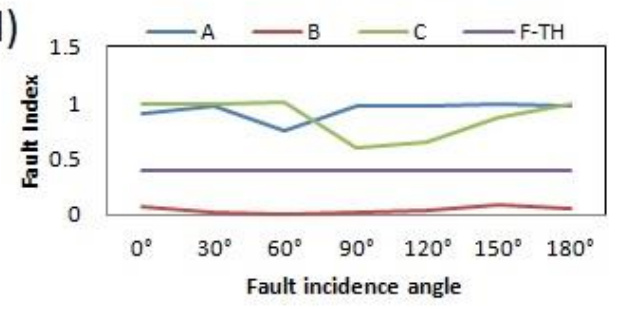

(f)

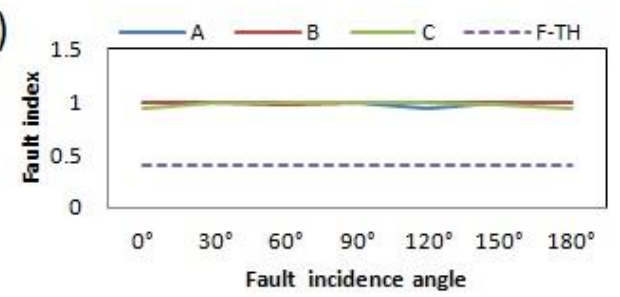

(h)

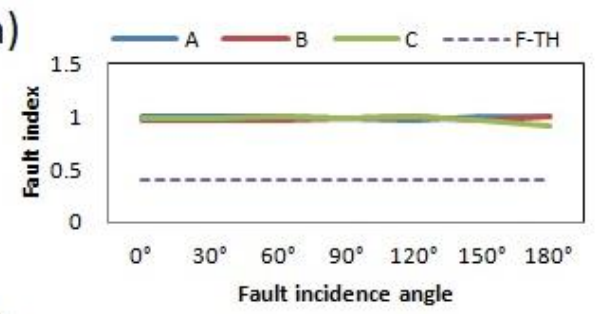

(j)

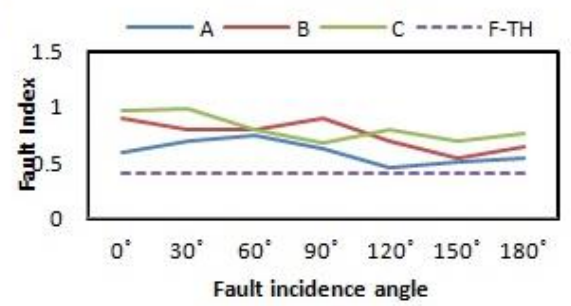

Figure 11. Variation of fault index with fault incidence angle: a) AB fault at DG-1,b) ABCG fault at DG-1,c) AG fault at DG-2,d) CA fault at DG-2, e) ACG fault at DG-3,f) ABCG fault DG-3,g) ABG fault at DG-4,h) ABCG fault at DG-4, i)CG fault at PCC, j) ABCG fault at PCC. 
However, the discrimination between double line and double line to ground faults cannot be judged by fault index alone. To discriminate between $\mathrm{AB}$ and $\mathrm{ABG}$ faults, zero sequence currents are required and these are compared with ground fault threshold $(\mathrm{GF}-\mathrm{TH}=1)$ to discriminate LLG from LL fault. From Fig.10, it is clear that the zero sequence current signals in case of ABG fault varies much more than GF-TH where as AB fault remains very low compared to GF-TH. Thus LL faults can be discriminated against LLG faults by using zero sequence currents.

\subsection{Variation of fault incidence angles}

To test the proposed algorithm at equal intervals of $30^{\circ}$ faults have been simulated. The variation of fault indexes of the three phases with the angle of fault incidence has been illustrated in Fig 11. It is apparent from Fig 11(c) and Fig 11(i) that the fault index of the faulty phase is greater than that of threshold for various angles of fault incidence for LG fault. It is illustrated from the Fig11 (e), Fig 11(g) and Fig 11(a), and Fig 11(d) that the fault index of the faulty phase is more than that of threshold value for different fault incidence angles of LLG and LL faults respectively. It is observed from Fig 11(b), 11(f), 11(h), and11(j) that the fault indexes of all the three phases are greater than the threshold value for different fault incidence angles in case of ABCG fault.

Table 2. Fault Detection Time at DG-1 During the Faults at DG1

\begin{tabular}{|c|c|c|c|c|c|c|}
\hline \multirow{3}{*}{$\begin{array}{l}\text { TYPE } \\
\text { OF } \\
\text { FAULT }\end{array}$} & \multicolumn{2}{|c|}{ PHASE A } & \multicolumn{2}{|c|}{ PHASE B } & \multicolumn{2}{|c|}{ PHASE C } \\
\hline & IS FAULT & DETECTION & IS FAULT & DETECTION & IS FAULT & DETECTION \\
\hline & PRESE NT & TIME(SEC) & PRESENT & TIME(SEC) & PRESENT & TIME(SEC) \\
\hline AG & YES & 0.0025 & NO & N.A & NO & N.A \\
\hline BCG & NO & N.A & YES & 0.0025 & YES & 0.0025 \\
\hline $\mathrm{CA}$ & YES & 0.0025 & NO & N.A & YES & 0.0025 \\
\hline ABCG & YES & 0.0025 & YES & 0.0025 & YES & 0.0025 \\
\hline \multicolumn{7}{|c|}{ Table 3. Fault Detection Time at Pcc During the Faults at DG1 } \\
\hline & \multicolumn{2}{|c|}{ PHASE A } & \multicolumn{2}{|c|}{ PHASE B } & \multicolumn{2}{|c|}{ PHASE C } \\
\hline FAUT T & IS FAULT & DETECTION & IS FAULT & DETECTION & IS FAULT & DETECTION \\
\hline & PRESENT & TIME(SEC) & PRESENT & TIME(SEC) & PRESENT & TIME(SEC) \\
\hline AG & YES & 0.0025 & $\mathrm{NO}$ & N.A & NO & N.A \\
\hline BCG & NO & N.A & YES & 0.0025 & YES & 0.00125 \\
\hline CA & YES & 0.0025 & NO & N.A & YES & 0.00375 \\
\hline ABCG & YES & 0.0025 & YES & 0.00125 & YES & 0.00125 \\
\hline
\end{tabular}

Table 4. Fault Detection Time at DG-4 During the Faults at DG-4

\begin{tabular}{ccccccc}
\hline \multirow{2}{*}{ TYPE OF } & \multicolumn{2}{c}{ PHASE A } & \multicolumn{2}{c}{ PHASE B } & \multicolumn{2}{c}{ PHASE C } \\
\cline { 2 - 6 } FAULT & IS FAULT & DETECTION & IS FAULT & DETECTION & IS FAULT & DETECTION \\
& PRESENT & TIME(SEC) & PRESENT & TIME(SEC) & PRESENT & TIME(SEC) \\
\hline AG & YES & 0.0025 & NO & N.A & NO & N.A \\
ABG & YES & 0.0025 & YES & 0.0025 & NO & N.A \\
BC & NO & N.A & YES & 0.0025 & YES & 0.0025 \\
ABCG & YES & 0.0025 & YES & 0.0025 & YES & 0.0025 \\
\hline
\end{tabular}

Table 5. Fault Detection Time at PCC During the Faults at DG-4

\begin{tabular}{ccccccc}
\hline \multirow{2}{*}{ TYPE OF } & \multicolumn{2}{c}{ PHASE A } & \multicolumn{2}{c}{ PHASE B } & \multicolumn{2}{c}{ PHASE C } \\
\cline { 2 - 6 } FAUL & IS FAULT & DETECTION & IS FAULT & DETECTION & IS FAULT & DETECTION \\
& PRESENT & TIME(SEC) & PRESENT & TIME(SEC) & PRESENT & TIME(SEC) \\
\hline AG & YES & 0.00375 & NO & N.A & NO & N.A \\
ABG & YES & 0.00375 & YES & 0.0025 & NO & N.A \\
BC & NO & N.A & YES & 0.0025 & YES & 0.00375 \\
ABCG & YES & 0.00375 & YES & 0.0025 & YES & 0.00375 \\
\hline
\end{tabular}

The above tables from (2-5) illustrate that the time to detect fault from incidence in seconds at DGs and PCC. From table- 2 and table-3, it is clear that fault is detected in $0.0025 \mathrm{sec}$ from incidence at both DG-1 and PCC in the case of AG fault. Similarly, from table- 4 and table-5 it is evident that fault is detected within the quarter cycle in all types of faults at both DGs and corresponding PCC.

\section{CONCLUSION}

The proposed algorithm investigates the successful implementation of the wavelet transform based alienation coefficient approach for effective detection of islanding, detection and classification of faults within quarter cycle and their discrimination in distribution systems with penetration of DGs. It is found that the islanding is less than threshold value and fault is greater than threshold value in all the cases. Thus the proposed 
algorithm is successful, reliable for the detection of islanding and fault and their discrimination. Detection of event can be done using alienation coefficients within quarter cycle of time.

\section{REFERENCES}

[1] El-Zonkoly, Amany M. Fault diagnosis in distribution networks with distributed generation. Electric Power Systems Research. Vol 81 no. 7, pp 1482-1490, 2011.

[2] "IEEE Recommended Practice for Utility Interconnected Photovoltaic (PV) Systems", IEEE Standard 2000; 9292000.

[3] "IEEE Standard for Interconnecting Distributed Resources into Electric Power Systems", IEEE Standard 1547TM, June 2003.

[4] T Funabashi, K Koyanagi, R. Yokoyama. "A review of islanding detection methods for distributed resources." In 2003 IEEE Bologna Power Tech Conference Proceedings, vol. 2, pp. 6, $2003 .$.

[5] J Yin, L Chang, C Diduch. "Recent developments in islanding detection for distributed power generation." In 2004 Large Engineering Systems Conference on Power Engineering, pp. 124-128. $2004 .$.

[6] H Karimi, A Yazdani, R Iravani. "Negative-sequence current injection for fast islanding detection of a distributed resource unit." IEEE Transactions on power electronics, vol 23, no. 1 pp. 298-307, 2008.

[7] Samantaray, S. R., Trupti Mayee Pujhari, and B. D. Subudhi. "A new approach to islanding detection in distributed generations." In 2009 International Conference on Power Systems, pp. 27-29, 2009.

[8] D Velasco, C Trujillo, G Garcera, E Figueres. "An active anti-islanding method based on phase-PLL perturbation." IEEE Transactions on Power Electronics, vol 26, no. 4 pp. 1056-1066, 2010.

[9] F Hashemi, A. Kazemi, S. Soleymani. "A new algorithm to detection of anti-islanding based on dqo transform." Energy Procedia, vol. 14, pp. 81-86, 2012.

[10] A Khamis, H Shareef, A Mohamed, E Bizkevelci. "Islanding detection in a distributed generation integrated power system using phase space technique and probabilistic neural network." Neurocomputing, vol 148 pp 587-599, 2015.

[11] WG Morsi, CP Diduch, L Chang. "A new islanding detection approach using wavelet packet transform for wind-based distributed generation," In Power Electronics for Distributed Generation Systems (PEDG). 2010 2nd IEEE International Symposium on, pp. 495-500. IEEE, 2010.

[12] H Karegar, B Sobhani, "Wavelet transform method for islanding detection of wind turbines," Renewable Energy, vol. 38, pp. :94-106, 2012.

[13] R Shariatinasab, "New islanding detection technique for DG using discrete wavelet transform," In: IEEE international conference on power and energy (PECon2010), pp. 294-299, 2010.

[14] Sk Abdul Gafoor, PV Ramana Rao, "Wavelet based fault detection, classification and location in transmission lines" in Proc. 2006 IEEE Power and Energy Conference, pp. 114-118, 2006.

[15] S Mahmood,M Nageswara Rao, Sk Abdul Gafoor, "A wavelet based protection scheme for distribution networks with Distributed Generation,” IEEE International conference ICETEEEM. Pp. 33-37, 2012.

[16] T Ackermann, G Andersson, L Soder. "Electricity market regulations and their impact on distributed generation." In International Conference on Electric Utility Deregulation and Restructuring and Power Technologies Proceedings, pp. 608-613, 2000.

[17] S Javad, B Ehsan, K Rasoul, “A new fault location algorithm for radial distribution systems using modal analysis," International Journal of Electrical Power \& Energy Systems, vol 45 no 1, pp. 271-278, 2013.

[18] L Yuan, "A novel method for locating faults on distribution systems," Electric Power Systems Research, vol. 117, pp. 21-26, 2014.

[19] SS Gururajapathy, H Mokhlis, HA Illias, "Fault location and detection techniques in power distribution systems with distributed generation: A review," Renewable and Sustainable Energy Reviews. vol 74, pp. 949-958, 2017.

[20] S Silva, C Pyramo, G Maury, L Alcyr, A Franciele, Daniel, "High impedance fault detection in power distribution systems using wavelet transform and evolving neural network,"Electric Power Systems Research. vol. 154, pp. 474483, 2018.

[21] Bhuvnesh R, Abdul Gafoor Sk. Wavelet-alienation based protection scheme for multi-terminal transmission line. Electric Power Systems Research. 2018; 161: 8-16.

[22] ME Masoud, MMA Mahfouz, "Protection scheme for transmission lines based on alienation coefficients for current signals," IET generation, transmission \& distribution. Vol. 4, no. 11, pp. 1236-1244, 2010.

[23] S Chatterjee, C Sivaji, KR Chinmoy, D Debangshu. "Wavelet network-based classification of transients using dominant frequency signature", Electric Power Systems Research, vol. 78, no. 1, pp. 21-29, 2008.

[24] J Bhaskar, S Uday, Sk Abdul Gafoor, J Amarnath. "Wavelet fuzzy based fault location estimation in a three terminal transmission system". In Advanced Computing and Communication Systems. 2015 International Conference on, pp. 1-6. IEEE, 2015.

[25] Shekar, S. Chandra, GRavi Kumar, and S. V. N. L. Lalitha. "A transient current based micro-grid connected power system protection scheme using wavelet approach." International Journal of Electrical and Computer Engineering, vol 9, no. 1, pp. 14, 2019.

[26] Qasaimeh, Malik, Rawan Turab, and Raad S. Al-Qassas. "Authentication techniques in smart grid: a systematic review." Telkomnika, vol. 17, no. 3, pp. 1584-1594, 2019.

[27] Yunus, AM Shiddiq, M Saini, A Abu-Siada. "Dynamic performance comparison of DFIG and FCWECS during grid faults." Telkomnika, vol. 17, no. 2, pp. 1040-1046, 2019.

[28] TA Nugroho, RS Wijanarko, H Setiadi. "Coordination of blade pitch controller and battery energy storage using firefly algorithm for frequency stabilization in wind power systems." Telkomnika, vol. 17, no. 2, pp. 1014-1022, 2019. 